\title{
Gender Gaps in PISA Test Scores: The Impact of Social Norms and the Mother's Transmission of Role Attitudes
}

\author{
AINARA GONZÁLEZ DE SAN ROMÁN ${ }^{\text {a }}$, SARA DE LA RICA ${ }^{\mathrm{b}}$ \\ a IE Business Scholl, IE University, Maria de Molina 31 BIS, 28006 Madrid, Spain. E-mail: \\ agod@faculty.ie.edu \\ b University of the Basque Country (UPV-EHU, FEDEA), Faculty of Economics, Avda. Lehendakari \\ Aguirre, 83, 48015 Bilbao, Spain.E-mail: sara.delarica@ehu.es
}

\begin{abstract}
The existence of gender gaps in test scores has been documented in the relevant literature for a wide range of countries. In particular, the Programme for International Student Assessment (PISA) conducted by the OECD over the past ten years reveals that on average girls underperform (outperform) boys in maths (reading) scores in most of the countries that take part in the evaluation programme. Focussing primarily on maths we find that differences in culture and social norms across countries and across regions within the same country are crucial determinants in understanding gender differences in PISA 2009 scores: girls perform relatively better in societies where gender equality is enhanced, and the effect varies over the distribution of scores. In addition, we find substantial evidence for the intergenerational transmission of gender role attitudes within the family, especially from mothers to daughters, as the relative performance of girls with respect to boys is better in families where the mother is active in the labour market.
\end{abstract}

Keywords: PISA, Test Scores, Maths, Achievement, Gender Differences, Culture, Role Attitudes and Intergenerational Transmission.

\section{Brechas de género en los resultados de PISA: El impacto de las normas sociales y la transmisión de roles de género de madres a hijas}

\section{RESUMEN}

La existencia de brechas de género en los resultados de las pruebas escolares se ha documentado en la literatura para una amplia gama de los países. En particular, el Programa para la Evaluación Internacional de Alumnos (PISA) llevado a cabo por la OCDE durante los últimos diez años, ha revelado que las niñas tienen en promedio un desempeño inferior (superior) a los niños en matemáticas (lectura) en la mayoría de los países que participan en el programa de evaluación. Basándonos principalmente en matemáticas, encontramos que las diferencias en la cultura y las normas sociales entre países, y entre regiones dentro del mismo país, son factores determinantes para entender las diferencias de género en los resultados de PISA 2009: las niñas lo hacen relativamente mejor en sociedades donde existe una mayor igualdad de género, y el efecto varía a lo largo de la distribución de resultados. Además, encontramos evidencia sustancial de la transmisión intergeneracional de los roles de género dentro de la familia, especialmente de madres a hijas, siendo el rendimiento relativo de las niñas con respecto a niños mejor en las familias donde la madre participa activamente en el trabajo mercado.

Palabras clave: PISA, resultados, matemáticas, logro, diferencias de género, cultura, roles de género, transmisión intergeneracional.

JEL codes: C14, C33, I21, I24, J16

\footnotetext{
* Financial support from the Spanish Ministry of Science and Innovation (ECO2012-35820), from the Basque Government (IT793-13) and from the Spanish Women's Institute ( $n^{\circ}$ 2011-0004-INV-00081) is gratefully acknowledged.
}

Artículo recibido en octubre de 2015 y aceptado en diciembre de 2015

Artículo disponible en versión electrónica en la página www.revista-eea.net, ref. ə-34104 


\section{INTRODUCTION}

The Programme for International Student Assessment (PISA) conducted by the OECD over the past ten years reveals that on average girls underperform (outperform) boys in maths competencies (reading competencies) in most of the countries that take part in the evaluation programme. For over a decade, researchers have paid attention to these gender differentials (Goldin 1994; Hausmann et al., 2008) as indicators of gender inequalities at early stages of life. Understanding these early differences between boys and girls is of crucial importance from economic and social perspectives since they may ultimately affect their choices of education and professional careers. In particular, the lower performance of girls relative to boys in maths may go at least some way towards explaining why women in most industrialized countries are significantly under-represented in technical college majors such us engineering and maths (Peri \& Anelli 2012; Cecci \& Williams 2007). Furthermore, these discrepancies in the choice of field of study affect the subsequent professional career and may help explain the gender differentials observed in the labour market in terms of wages, promotion, job stability and status.

The study of the determinants of gender differences in math skills has been a major focus of academic research by not only economic and social researchers but also by biologists. There are basically two distinct schools of thought: those who stress that they are mainly the result of biological differences (nature) and those who stress the importance of cultural and social gender inequalities (nurture). Supporters of the first school argue that innate differences in spatial ability (Lawton \& Hatcher 2005), strategy (Kucian et al., 2005), or brain development (Gallagher \& Kaufman 2005) account for most of the gap in achievement.

Contrary to these studies, other authors find no significant differences in overall math aptitudes between boys and girls but differing social pressures instead (Spelke 2005). Closely related to this evidence, the hypothesis that nurture is the main determinant of gender differences in scholastic achievement is based on the idea, first proposed by Baker et al. (1993), that those differences are a result of social gender stratification. They hypothesized that the higher scores obtained in math tests by male students compared to their female counterparts reflected gender inequalities in the educational and economic opportunities available in a given culture. This proposition has obtained a great deal of support from the empirical perspective. For instance, Riegle-Crumb (2005), using cross-national data from the Third International Mathematics and Science Study (TIMSS), supports this hypothesis for the US. The relationship between social norms and the gender gap in test scores has also been documented across OECD countries. Guiso, Monte, Sapienza \& Zingales (2008) make use of the 2003 PISA survey and construct several measures of the 
degree of gender equality of a country -e.g. the Gender Gap Index (World Economic Forum). They find a higher math performance by girls in countries with more gender-equal cultures.

Alongside the theoretical and empirical interest in the study of the determinants of gender differences in scholastic achievement, another body of research has focussed on the economic and social consequences of gender inequalities in education. Several authors in this field highlight that inequality in education can negatively impact macroeconomic variables such as economic growth (Dollar \& Gatti 1999; Klassen 2002) or fertility (Basu 2002). Policy measures directed at enhancing female education not only help increase income and growth, as a result of the increase in human capital, but also lead to additional positive intergenerational transfers through the positive influence of mothers on the education and health of their children (Schultz 2002; Doepke \& Tertilt 2009).

The transmission of gender role attitudes across generations has also been the focus of a large proportion of recent research on labour market outcomes. Having a working mother has been found to influence strongly not only children's behaviour but also the gender role attitudes of adolescents (see Burt \& Scott, 2002). Along the same lines, Farré \& Vella (2013) find that mothers with less traditional views about the role of women in society are more likely to have working daughters. A related study by Fernández et al. (2004) highlights the increasing number of men growing up in families with working mothers as an important factor in explaining the increase in women's involvement in the labour force. Moreover, changes in gender role attitudes over time appear to map very well with changes in female labour force participation across OECD countries (Fortin 2005). However, the role of culture and its implications for economic behaviour across generations is relatively unexplored in empirical studies on scholastic achievement. Our paper seeks to help fill this gap.

More specifically, by focussing on the relative underperformance of girls in maths this paper gives empirical support to both the social gender stratification theory and the intergenerational transmission of gender roles. With respect to the former, we confirm and extend the social gender stratification hypothesis by updating previous results to the 2009 PISA survey and by adding new gender equality measures to those already used in the previous literature ${ }^{1}$; moreover, we extend the analysis to relate social norms to gender differences in maths test scores across regions within the same country, which constitutes a more homogeneous institutional setting. We make use of regional variation in Spain for a variety of reasons: first, Spain is the unique country in PISA 2009 where

${ }^{1}$ Currently, we are trying to update the analysis to the latest available PISA survey - 2012. Preliminary results indicate a change in the gender gap in maths, and we are exploring the extent to which the recession might be under such a change. This analysis, however, is out the scope of this paper. 
regional disaggregation allows the analysis across regions. Second, the education system is decentralised across regions so that regional governments decide on the management and organisation of education. Hence regional differences in the gender gap may emerge as a result of distinct views of social gender stratification ${ }^{2}$. Our results indicate that girls perform better in more gender-equal societies - be the countries or regions within a country.

With respect to the intergenerational transmission of gender roles we investigate whether gender role attitudes, measured as in previous studies by the mothers' labour market situation, can help to explain at least part of the gender differences observed in maths competencies. In particular, taking as given the strong evidence of Farré \& Vella (2013), we test whether attitudes towards gender roles are transmitted from generation to generation, and measure the implications of this cultural transmission in terms of children's educational achievement. Our results at the international level indicate that having a mother who participates in the labour market increases the daughter's performance in maths, an effect which is especially sharp for girls at the bottom part of the distribution of scores. This effect is indeed stronger in countries with low female labour force participation (below average), and hence in societies where such mothers "make a difference" in terms of gender role attitudes relative to their counterparts. Interestingly, such transmission is found to be even stronger when we restrict the analysis to Spain, which belongs to the group of lowparticipating countries, and in this case it is mainly driven by the most-highly educated participating mothers.

The remainder of the paper is organised as follows. Section 2 addresses the relevant data issues and provides a brief summary of the differences in children's scholastic achievement across countries in both maths and reading. Section 3 provides both descriptive and parametric evidence on culture and social norms across countries and analyses the implications for the gender differences observed in maths performance. Section 4 further investigates the extent to which gender role attitudes within the family, measured by the participation of mothers and fathers in the labour market, may be transmitted across generations, provides some evidence on the mechanisms that could be behind such intergenerational transmission, as well as several robustness checks for the validity of the results. Section 5 focuses on a more homogeneous institutional framework by restricting the study to a single country: Spain. It carries out an analysis similar to that of the two previous sections making use of the regional

\footnotetext{
${ }^{2}$ Although the gender gap across regions has not been explicitly accounted for before, some related papers have attempted to explain regional differences in test scores. Using PISA 2006 Ciccone \& García-Fontes (2009) compare the education systems in Catalonia and the rest of Spain. Studies for other European countries include the paper by Bratti et al. (2007), which analyses the differences in PISA 2003 results between the three Italian macro areas.
} 
disaggregation of Spain in the PISA 2009 data set. Section 6 concludes with a summary of our findings.

\section{DATA}

PISA is a rich data set at student and school levels with information on test scores for 15-year-old students in OECD and partner countries. The survey covers results in three fields: maths, reading and science. Background questionnaires are completed by students and school principals which help to provide detailed information on children, family and school characteristics. The PISA sample is stratified at two stages. First, schools are randomly selected; and second, students at each school are randomly assigned to sit the test in all three subjects. Test scores are scaled to have a mean of 500 and a standard deviation of 100 in the OECD student population. PISA assigns a probability distribution to the response pattern in each test. These values are called plausible values because they represent alternative estimates of students' ability that could have been obtained. OECD recommends estimating the scores from each plausible value (5 values) and obtain the arithmetic average of the five estimates (for the mean and for the standard errors). We also conducted the analysis using the first plausible value for any estimation rather than the arithmetic average of all five. Although the magnitude of the effect varies slightly, the results are qualitatively the same in all cases. The reported estimates in the paper are indeed those resulting from the use of the first plausible value.

The data set covers 475,460 students attending year seven or above at 17,093 schools in 64 countries, 34 of which belong to the OECD. Liechtenstein is dropped from the data set because it provides only 329 observations, which makes any calculation at the tails of the distribution problematic. We end up with 475,131 students at 17,081 schools in 63 countries $^{3}$.

Overall, the range of scores from country to country is wide, representing large differences in how well students can read and think mathematically. The mean maths score is 465.35 across the 63 countries in our sample and 499.70 across OECD countries. The partner countries Shanghai-China and Singapore show mean maths scores that are much higher than those of any other country that participated in PISA 2009. Shanghai-China is furthest ahead, with students there having scores more than 35 points higher, on average, than those in any other country (around 100 points above the OECD average and more than 130 points above the overall average). Korea is the top-performing OECD country (46.3 points above the OECD average), closely followed by Finland, which was

\footnotetext{
${ }^{3}$ For the sake of comparability with the results of Guiso et al. (2008), we use both the entire sample of countries available for 2009 and the set of countries used in that paper (the 40 countries that took part in PISA 2003).
} 
the PISA winner in 2003. Australia, Belgium, Canada, Chinese-Taipei, Denmark, Estonia, Germany, Hong Kong, Iceland, Japan, Netherlands, New Zealand, Slovenia and Switzerland all score significantly above the OECD average in maths. On the other side, the worst performing countries (more than 100 points below the OECD average) are Albania, Argentina, Brazil, Colombia, Indonesia, Jordan, Kyrgyzstan, Panama, Peru, Qatar and Tunisia. Within the OECD Chile and Mexico are better placed but still show a significant difference of close to 70 points. Spanish students score on average 483.71, similar to the average for the US and neighbouring countries such as Italy or Portugal. Austria, Czech Republic, France, Norway, Poland, Sweden and the UK show no significant differences from the OECD average.

The average score for reading skills is 457.16 across the sample of 63 countries and 489.81 across OECD countries. Shanghai-China also shows the highest average reading performance (65 and nearly 100 points above the OECD and the overall averages respectively), closely followed by Korea and Finland. Australia, Canada, Hong Kong, Japan, New Zealand and Singapore score at least 20 points above the OECD average. Belgium, Estonia, Iceland, Netherlands, Norway, Poland and Switzerland also perform significantly better than the OECD average but with smaller differences. The lowest performing countries at reading are the same as those reported for maths, with Colombia being the worst with a difference of close to 100 points. Spain is around 10 points below the average, a similar significant difference to that of Greece and Italy.

\section{CULTURE AND GENDER DIFFERENCES IN TEST SCORES ACROSS COUNTRIES}

This section focuses on gender differences across countries in test scores. As a descriptive device and for the sake of comparability with Guiso et al. (2008) we document gender differences in both maths and reading in an attempt to identify changes that took place between 2003 and 2009. To that end we compute gender differences in test scores for each country by running a regression of the maths and reading scores separately on a constant and a gender indicator (which is 1 if the student is female), where each observation is weighted by the student's final weight. In most countries boys have better scores in maths than girls, and the differences are statistically significant for 44 out of the 63 countries. In the remaining countries there is no statistical gender difference in maths skills ${ }^{4}$. There are isolated cases in which girls outperform

\footnotetext{
${ }^{4}$ Here top-performing countries such as Shangai-China, or Finland, Korea, and Sweden can be found among OECD participants, but also low performers such us Panama, Jordan or Indonesia,
} 
boys (e.g. Albania, Lithuania, Trinidad \& Tobago, Qatar and Kyrgyzstan). Figure 1 depicts gender differences in maths and reading scores for a set of selected countries. Countries are ranked in ascending order by their gender gap in maths scores.

Figure 1

Gender difference in test performance for a set of selected

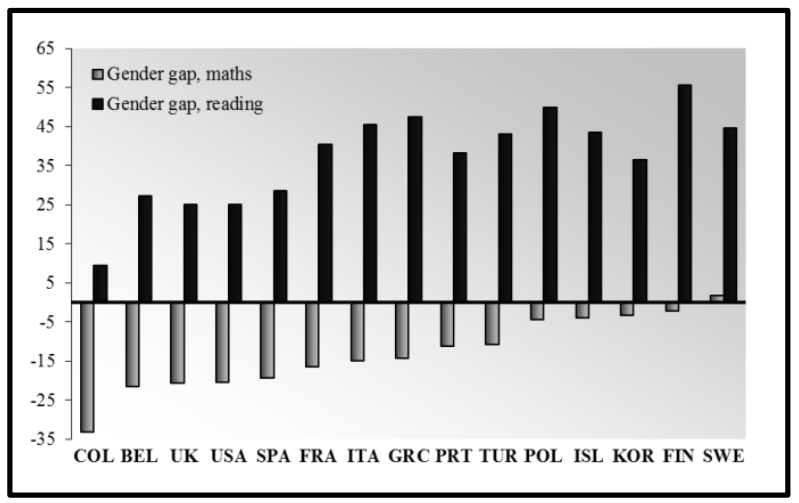

Source: Own elaboration.

On average girls' maths scores are 8.64 lower than those of boys (10.75 lower across Guiso countries and 12 lower across OECD countries) but the results vary considerably from country to country. The biggest difference is found in Colombia (-33.32) whereas in Sweden girls outperform boys (by 1.08). Spain ranks $7^{\text {th }}$ out of 63 countries in the average gap in maths with -19.32 points. In neighbouring countries such as Italy, France and Portugal the difference in maths between girls and boys is smaller than in Spain. The figure also reveals that the gender gap is reversed in reading ${ }^{5}$. Girls score on average 40.54 higher than boys in reading (around 39 points across Guiso countries and OECD countries), and the gap is positive and statistically significant for all countries, although there are major quantitative differences - for instance, in Colombia the difference is 9.46 and in Finland it is 55.53. The advantage in reading of Spanish girls is below average (28.66) and is similar to the corresponding gap for the United Kingdom and the United States. A comparison of this figure with a similar one constructed by Guiso et al. (2008) for the PISA 2003 survey reveals major changes in the gender gaps in some countries in this six-year

which makes it difficult to establish a relationship between average performance and gender differences in achievement.

5 This is consistent with prior literature, both for the US (Baker \& Jones 1993; Fuchs \& Woessmann, 2007; Fryer \& Levitt 2009) and for most of the PISA participating countries (Guiso et al. 2008). 
period. For example, the UK has shifted from a negligible gender difference in maths in 2003 to one of the biggest gaps in 2009 (similar patterns are found for the US and Belgium). The opposite has happened in the emerging economy of South Korea. Overall, the average gender gap in maths has remained stable but the average gap in reading has widened ${ }^{6}$ (from 32.70 to 38.78).

Figure 2 shows the correlation between the average gender gaps in maths and reading across countries (with Colombia excluded as an outlier), which is 0.7764 . This means that in those countries where girls have a bigger advantage in reading relative to boys they also tend to have smaller disadvantage in maths. The correlation is around 18 percentage points higher than that shown by Guiso et al., for 2003.

Figure 2

Correlation between gender gaps across PISA 2009 countries

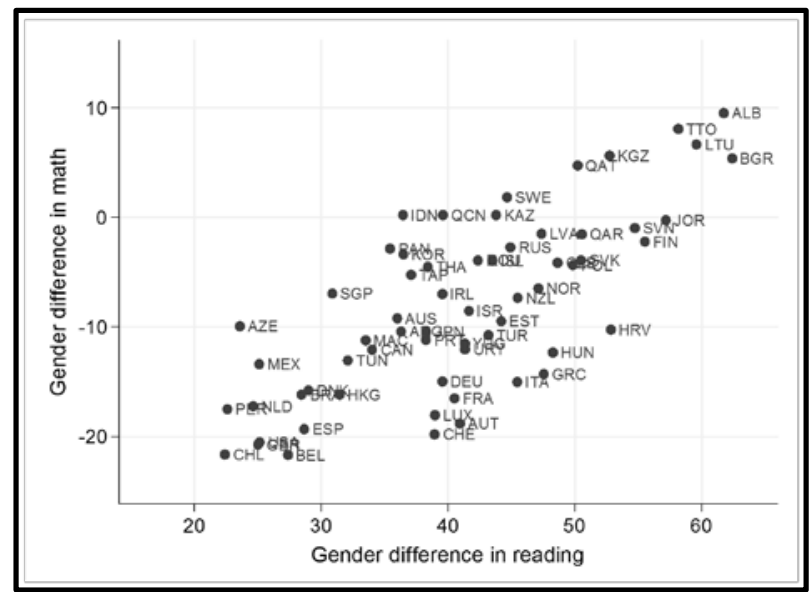

Source: Own elaboration.

Moreover, gender differences in test scores differ significantly in different parts of the achievement distribution range. Table 1 shows the gender gap between countries in maths and reading for the different percentiles of the test score distribution. Among high-achieving students, girls do relatively worse in maths than boys and lose much of the advantage that they hold in reading, which directly translates into more gender inequality at the top end of the distribution. As already shown in related studies (Klassen 2002) these gender inequalities, especially among the best students, could negatively affect girls'

\footnotetext{
${ }^{6}$ In some countries the reason is that girls' reading performance has improved considerably; but in others, such as France and Sweden, the main reason is a decline in boys' performance.
} 
future earnings throughout their chosen professional careers, which would result in persistence of gender inequality at older ages.

Table 1

The International Gender Gap in Maths \& Reading Test Scores

\begin{tabular}{lcccccccc}
\hline & Mean & Std Dev & 5th & 10th & 25th & 75th & 90th & 95th \\
\hline Maths Score & & & & & & & & \\
\hline Boys & 471.82 & 106.50 & 293.51 & 326.23 & 384.02 & 536.54 & 605.01 & 640.92 \\
Girls & 463.18 & 101.72 & 286.50 & 318.05 & 373.74 & 517.77 & 582.58 & 620.59 \\
Gender Gap & $\mathbf{- 8 . 6 4}$ & & $\mathbf{- 7 . 0 1}$ & $\mathbf{- 8 . 1 8}$ & $\mathbf{- 1 0 . 2 8}$ & $\mathbf{- 1 8 . 7 7}$ & $\mathbf{- 2 2 . 4 3}$ & $\mathbf{- 2 0 . 3 3}$ \\
\hline Reading Score & & & & & & & & \\
\hline Boys & 444.58 & 103.05 & 278.87 & 313.34 & 373.07 & 517.93 & 581.42 & 615.81 \\
Girls & 484.90 & 98.08 & 319.76 & 351.50 & 409.41 & 544.78 & 604.60 & 637.65 \\
Gender Gap & $\mathbf{4 0 . 3 2}$ & & $\mathbf{4 0 . 8 9}$ & $\mathbf{3 8 . 1 6}$ & $\mathbf{3 6 . 3 4}$ & $\mathbf{2 6 . 8 5}$ & $\mathbf{2 3 . 1 8}$ & $\mathbf{2 1 . 8 4}$ \\
\hline
\end{tabular}

Source: Own elaboration.

\subsection{Measures of Gender-equal Societies}

Given that the main empirical question that we address in this section is the extent to which girls perform better in traditionally "masculine" subjects in more gender-equal societies, the analysis that follows is performed only for the math competency ${ }^{7}$. For the sake of comparability, we first construct for 2009 similar gender-equality measures to those already used in the relevant literature (Fortin 2005; Guiso et al., 2008; Farré \& Vella 2013) summarizing the gender role attitudes of countries towards women. The set of countries for which information is available differs depending on the measure. Higher values in any of the measures that we describe below indicate a better position of women in society.

(1) The Gender Gap Index (GGI), or women's emancipation index, is taken from the 2009 Global Gender Gap report prepared by the World Economic Forum and synthesises the position of women in any given country by taking into account economic opportunities, economic participation, educational attainment, health and well-being.

(2) The Political Empowerment Index, from the same source, measures women's political participation and is based on three components: (i) the ratio of women to men with seats in parliament; (ii) the ratio of women to men at ministerial level; (iii) the ratio of the number of years with a woman as head of state to the years with a man.

\footnotetext{
${ }^{7}$ In addition, the high correlation observed between the gender gap in maths and reading across countries makes it unnecessary to develop the whole analysis for the two subject areas. The results found for the math competency also apply to reading skills.
} 
(3) The Average World Value Survey (WVS) Indicator, which is constructed by averaging the level of disagreement with a series of statements on the role of women in society, such us "When jobs are scarce, men should have more right to a job than women"- taken from all waves of the World Value Survey.

We add another set of measures ${ }^{8}$ which are more related to how men and women use their time at home and with regard to the decision to participate in the labour market. Both can be also considered as proxies for the gender culture of a country and higher values also point to a better position of women in society.

(4) The Female Labour Force Participation Rate 15 or more (FLFP 15+), taken from the International Labour Organization (ILO) website, represents the proportion of the female population aged 15 and older who were active (either working or searching for a job) in the labour market in 2009.

(5) The Female Labour Force Participation Rate 35-54 (FLFP 35-54): Like measure (4) this is taken from the ILO. It is defined as the proportion of the females aged 35 to 54 years who actively participated in the labour market in 2009. We use this measure since it represents a particular cohort of women which roughly coincides with the age range of the mothers of our PISA students.

(6) The Gender Housework Ratio from the Harmonized Time Use Survey (2003) which is defined as the ratio of time devoted to housework (men/women). ${ }^{9}$

Table 2

Summary statistics of the different measures of gender-equal societies

\begin{tabular}{lccc|ccc}
\hline & \multicolumn{3}{c|}{ All Countries } & \multicolumn{3}{c}{ Countries in Guiso et al. (2008) } \\
\hline & Average & Std Dev & Obs. & Average & Std Dev & Obs. \\
\hline Women's emancipation & 0.703 & 0.052 & 59 & 0.713 & 0.058 & 37 \\
Political Empowerment & 0.199 & 0.142 & 59 & 0.239 & 0.157 & 37 \\
Avg WVS Indicator & 2.715 & 0.186 & 32 & 2.715 & 0.186 & 32 \\
FLFP 15+ & 0.519 & 0.095 & 62 & 0.527 & 0.096 & 40 \\
FLFP 35-54 & 0.729 & 0.149 & 62 & 0.748 & 0.141 & 40 \\
Gender Housework ratio & 0.529 & 0.148 & 22 & 0.521 & 0.163 & 18 \\
\hline
\end{tabular}

Source: Own elaboration.

\footnotetext{
${ }^{8}$ All indicators range from 0 to 1 except for the Average World Value Survey Indicators which ranges from 0 to 5. For the sake of comparability with Guiso et al. (2008) we have not standardized the indicators and use them instead as they do in their paper.

${ }^{9}$ The Gender Housework Ratio is not available for 2009. However, the persistence over time of women's attitudes as homemakers documented in previous studies (See Fortin 2005) justifies its inclusion for 2003.
} 
Sample statistics for all measures for both the full set of available countries and the same set of countries as in Guiso et al., (2008) are reported in Table 2. There is little difference between the statistics from the two different samples. The sample with the smaller set of countries, mainly the most developed ones, has slightly higher averages for the different measures and similar standard deviations.

The relationship between the various gender equality measures is shown in Table 3, which gives one by one correlation coefficients for the full set of available countries in 2009 (no significant differences if the Guiso sample is used instead). Several interesting features deserve attention. First, all correlations are positive and significant. Second, the close correlations of the Gender Housework Ratio with the other measures already used in the relevant literature suggest that the former can also be used as a proxy for gender equality; moreover, the high correlation of this measure with FLFP measures suggests that the more collaborative men are at home the easier it is for women to join the labour market. Finally, the positive correlation of the Average WVS indicator with the participation measures is in line with previous studies (Fortin 2005; Farré \& Vella 2012) that find a clear, positive association between gender role attitudes and FLFP.

Table 3

Correlation between gender-equality measures across countries

\begin{tabular}{l|cccccc}
\hline & GGI & $\begin{array}{c}\text { Political } \\
\text { Emp. }\end{array}$ & $\begin{array}{c}\text { Avg. } \\
\text { WVS }\end{array}$ & $\begin{array}{c}\text { FLFP } \\
\mathbf{1 5 +}\end{array}$ & $\begin{array}{c}\text { FLFP } \\
\mathbf{3 5 - 5 4}\end{array}$ & $\begin{array}{c}\text { Housework } \\
\text { ratio }\end{array}$ \\
\hline GGI & 1 & & & & & \\
Political Emp. & 0.8729 & 1 & & & & \\
Avg WVS Index & 0.7454 & 0.6879 & 1 & & & \\
FLFP 15+ & 0.7166 & 0.4977 & 0.6251 & 1 & & 1 \\
FLFP 35-54 & 0.6885 & 0.3829 & 0.4120 & 0.7736 & 1 & \\
Housework ratio & 0.8457 & 0.7009 & 0.6993 & 0.8308 & 0.8528 & 1 \\
\hline
\end{tabular}

Source: Own elaboration.

\subsection{Gender Equality Measures and Gender Differences in Math Test Scores}

We next analyse the extent to which these measures affect the gender differences observed in maths scores following two different approaches. First, we carry out a cross-country analysis where the unit of observation is the country. Secondly, to avoid any potential underlying unobserved heterogeneity problem, we estimate the impact of these measures directly in our sample of 2009 PISA students. 


\section{A) Cross-country analysis}

To assess the correlation between measures of gender equality and the gender difference in maths scores we run OLS regressions of the dependent variable - the average gender gap in maths - on each measure of gender equality plus a constant and the $2009 \log$ GDP per capita ${ }^{10}$. The baseline estimation equation for country $j$ reads as follows:

$$
\operatorname{Gap}_{j}=a+\beta M_{j}+\tau \log G D P_{j}+u_{j}
$$

$M=$ [GGI, Pol. Empowerment, Avg WVS Ind, FLFP 15+, FLFP 35-54, Housework Ratio]

where $j=1, \ldots, J, J$ stands for the total number of countries for which each component of $M$ is available and $u_{j}$ is the stochastic error term. The left-handside variable is a $(J \times 1)$ vector that contains the averages at the country level of the maths gender gap. Equation [1] is estimated separately for the six measures included in $M . \quad a, \beta$ and $\tau$ are the set of coefficients to be estimated. For the sake of comparability with Guiso et al. (2008) we restrict the sample to the 40 countries also available in $2003^{11 .}$ The estimation results -in particular, the estimated coefficients $\hat{\beta}$ and $\hat{\tau}$ - and the number of countries for which each measure is available are reported in Table 4.

We find a positive and significant correlation between the gender gap in maths and each of the gender equality measures. In addition, similar results are observed from the new measures that we have incorporated, i.e. the housework ratio and FLFP aged 35-54. Hence, in countries where women have a better relative position (more gender-equal societies such as those of the Nordic countries) girls become better in maths and thus narrow the gender gap. This confirms the results found by Guiso et al. (2008) for the 2003 PISA wave. The magnitude of the coefficients varies considerably across measures in Table 4, but the scale is different in each case so they are not directly comparable. For example, our statistical model suggests that if Spain had the same degree of female participation as Sweden (a top gender-equality country) the mean maths performance of girls would increase by 5.3 score points, which would eliminate one third of the Spanish gender gap in maths ${ }^{12}$. If Spain had the gender

${ }^{10}$ In line with the importance of controlling for income in the cross-country analysis already pointed out in related studies, we take the 2009 real GDP per capita deflated with Laspeyres price index from the Penn World Table 7.0.

${ }^{11}$ When the cross-country analysis is conducted with the full sample of available countries, correlations are still positive but lower and in some cases not statistically significant.

${ }^{12}$ To compute this counterfactual statistic we use the equation for the FLFP from the estimation in Table 4 as follows: 5.3 = Estimated coefficient $*$ (FLFP Sweden - FLFP Spain $)=42.32$ (0.616-0.491). We could follow the same procedure to compute similar statistics for a comparison between any two other countries. 
housework ratio or GGI of Sweden the gap would be reduced by 6.09 and 7.02 points respectively.

\section{Table 4}

OLS estimation - Dep. Variable: Gender Gap in Maths Test Scores

\begin{tabular}{|c|c|c|c|c|c|c|}
\hline GGI & $\begin{array}{l}90.13^{\star \star \star} \\
(19.54)\end{array}$ & & & & & \\
\hline Political & & $24.03^{\star \star \star}$ & & & & \\
\hline Empowerment & & (6.74) & & & & \\
\hline $\begin{array}{l}\text { Avg. WVS } \\
\text { indicator }\end{array}$ & & & $\begin{array}{l}17.13^{* \star} \\
(7.01)\end{array}$ & & & \\
\hline FLFP 15+ & & & & $\begin{array}{l}42.32^{\star \star \star *} \\
(7.98)\end{array}$ & & \\
\hline FLFP 35-54 & & & & & 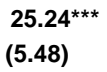 & \\
\hline $\begin{array}{l}\text { Housework } \\
\text { ratio }\end{array}$ & & & & & & $\begin{array}{l}33.41^{\star * *} \\
(10.71)\end{array}$ \\
\hline $\begin{array}{l}\text { Log GDP } \\
\text { p.cap, } 2009\end{array}$ & $\begin{array}{c}-9.30^{\star * *} \\
(1.84)\end{array}$ & $\begin{array}{c}-7.91^{\star \star *} \\
(1.79)\end{array}$ & $\begin{array}{l}-5.19^{\star} \\
(2.59)\end{array}$ & $\begin{array}{c}-6.77^{\star \star \star} \\
(1.53)\end{array}$ & $\begin{array}{c}-6.73^{\star \star \star} \\
(1.72)\end{array}$ & $\begin{array}{c}-13.36^{\star * \star} \\
(3.57)\end{array}$ \\
\hline Countries & 37 & 37 & 32 & 40 & 40 & 18 \\
\hline$R^{2}$ & 0.462 & 0.325 & 0.189 & 0.379 & 0.311 & 0.279 \\
\hline
\end{tabular}

Note: Robust standard errors in parentheses. ${ }^{* * *} p<0.01$, ** $p<0.05,{ }^{*} p<0.1$. Each column presents the coefficients of a separate regression. Country factor weights are used in the estimations.

Source: Own elaboration

\section{B) Analysis at student-level : Pool of countries}

The cross-country analysis has clear drawbacks from a statistical point of view. First, unobserved heterogeneity may drive spurious correlations between the gender gaps and the gender equality measures presented. Moreover, from 40 observations it is not possible to reach any robust result - they serve mainly as a motivational device. Therefore, we now take advantage of the nature of the PISA data by using variables at individual (student) level to try to avoid spurious correlations between unobservable factors and measures of genderequal societies. We estimate the individual maths scores denoted by $T$ for all students in the PISA 2009 sample on a set of demographic, family and school variables denoted by $X^{13}$, as well as an indicator for Female and interactions between the gender equality measures, at the country level, and Female. We also include country fixed effects $\left(\eta_{j}\right)$ and an interaction term between Female

${ }^{13}$ Individual level controls include dummies for any students who are in a grade different from the modal one in the country, the immigration status of the child, an indicator for nuclear families (i.e. living with both parents), parental education level (university), parental occupational status and cultural possessions at home. School level controls include school type (private), percentage of girls and student-teacher ratio. Adding or removing controls changes neither the sign nor the significance of the estimated coefficients of interest. 
and the $2009 \log$ GDP per capita to ensure that any improvement in maths scores is related not just to economic development but to improvements in the role of women in society. The specification is given by the following equation:

$$
T_{i j}=a+\text { bFemal }_{i}+\gamma X_{i}+\beta \text { Female }_{i} * M_{j}+\mu \text { Female }_{i} * \log G D P_{j}+\eta_{j}+\varepsilon_{i}
$$

where $i=1, \ldots, N, N$ stands for the total number of students and $\varepsilon_{i}$ is the stochastic error term. The dependent variable is a $(N \times 1)$ vector that contains the math test score for each student $i$. Equation [2] is estimated separately for the six measures in $M$. A positive and significant coefficient for the interaction term between Female and the corresponding gender equality measure (namely $\hat{\beta}>0$ ) indicates that the more gender equal the society is, the higher the score for girls is. Table 5 presents the estimation results for the whole set of countries in PISA 2009. Estimations are drawn up at the average level and also for the $25^{\text {th }}$ and $75^{\text {th }}$ quantiles to see whether societal gender equality indicators affect students differently at different points of the score distribution range. Each cell in the table presents the coefficient for the interaction between Female and the corresponding gender equality measure from a different estimation.

Table 5

Culture - The impact of Gender-equality measures on Girls' Scores

\begin{tabular}{lccc}
\hline & Average & 25th & 75th \\
\hline Female*GGI & $53.45^{\star \star \star}$ & $48.45^{\star \star \star}$ & $57.38^{\star \star \star}$ \\
Female*Political empowerment & $(12.72)$ & $(13.79)$ & $(13.22)$ \\
& $14.78^{\star \star \star}$ & $14.15^{\star \star}$ & $25.57^{\star \star \star}$ \\
Female*Avg WVS indicator & $(5.53)$ & $(7.54)$ & $(6.21)$ \\
Female*FLFP15+ & -1.16 & -8.74 & 7.07 \\
Female*FLFP 35-54 & $(4.85)$ & $(5.77)$ & $(5.77)$ \\
& $38.13^{\star \star \star}$ & $36.98^{\star \star *}$ & $35.26^{\star \star \star}$ \\
Female*Housework ratio & $(5.14)$ & $(6.54)$ & $(6.31)$ \\
& $35.41^{\star \star \star}$ & $34.38^{\star \star *}$ & $32.73^{\star \star \star}$ \\
\hline
\end{tabular}

Notes: Robust standard errors in parentheses. $* * * p<0.01, * * p<0.05, * p<0.1$. Individual level controls, school variables and country fixed effects are included. Iceland is taken as the country of reference. An interaction term of Female with the log GDP per capita of 2009 is also included. Students' weights are used in the estimations. Observations $\left(R^{2}\right)$ range from $174,755(0.29)$ to $361,083(0.45)$ depending on the measure.

Source: Own elaboration.

At a glance, the first thing that stands out from Table 5 is that most interactions between Female and the gender equality measures are positive and significant, at the average and also at the tails of the distribution, except for the Average 
WVS Indicator ${ }^{14}$. This confirms that girls perform better in maths in more gender-equal societies. It is also consistent with the positive correlations already revealed by the cross-country analysis performed previously, which indicates that those correlations were not just driven by unobserved heterogeneity. Focussing on the results at the tails of the distribution range we observe that the impacts of some of the indicators (GGI, Political Empowerment and Gender Housework Ratio) are stronger for high-achieving females. Given that the gap is greater precisely at the right tail - as seen in Table 1, this fact helps close the gap throughout the maths score distribution. By contrast, we find no statistical differences along the distribution for the reduction of the gap in maths associated with measures related to the participation of women in the labour market, which suggests differences in terms of interpretation between these two groups of indicators.

In summary, the international analysis in this section reveals that in approximately $70 \%$ of the PISA 2009 participating countries girls underperform boys in maths. The differences are exacerbated to the detriment of girls among high-achieving students. By constructing several gender equality measures at country level, we find a positive and significant correlation between those indicators and the maths gender gap, an effect which is even stronger at the upper end of the distribution.

\section{INTERGENERATIONAL TRANSMISSION OF GENDER ROLE ATTITUDES}

So far we have focussed on the impact of social gender roles on the average performance of boys and girls in PISA maths scores. However, one could seek to go much further and see whether those gender roles are transmitted across generations within the family. The PISA 2009 dataset provides information on the labour status of the students' parents. We construct the dummy variable Mother's Participation which is set to 1 if the student reports having a mother who is working or looking for a job and 0 otherwise. In order to test whether the participating mothers in our sample are representative of female labour force participation as a whole we take the average of this dummy across countries (for clarity of exposition we refer to this variable as Mothers' Participation) for comparison with the participation measures already constructed. It is very interesting to note that the correlation of our variable Mothers' Participation from the PISA sample with the FLFP $15^{+}$is quite high (0.721), and the

${ }^{14}$ Qualitatively similar results obtained with the set of 40 participating countries in 2003 are available upon request. A comparison of these results with those of Guiso et al. (2008) for the 2003 PISA sample shows that ours are higher except for FLFP 15+, which is somewhat lower in our estimation. 
correlation between Mothers' Participation and FLFP 35-54 is even higher and indeed almost perfect (0.9624).

This goes some way towards confirming that the mothers of the students in our sample are a fairly representative sample of females in that age cohort ${ }^{15}$ and, more importantly, it allows us to interpret the dummy Mother participate as a measure of gender role attitudes within the family context, which is actually quite consistent with the related literature. Therefore, instead of using country averages of gender equality measures and interacting them with a Female indicator, we directly analyse whether individual maths scores are affected by the labour market status of a student's mother (participant or not), and whether this impact differs by gender.

\subsection{The Impact of Parental Labour Status on Children's Scores}

We perform this analysis by running OLS regressions of the maths score on a set of demographic, family and school variables, as before, as well as the indicators for Female, Mother participate and the interaction between the two. We do the same with regard to the father's labour status to learn more about the transmission of gender roles, so we also include an indicator for the father being a full-time worker and its interaction with Female $^{16}$. The baseline equation estimated reads as follows:

$$
\begin{aligned}
T_{i j}= & a+\text { bFemale }_{i}+\beta_{1} \text { Mother participate }_{i}+\beta_{2} \text { Female }_{i} * \text { Mother participate }_{i}+ \\
& +\alpha_{1} \text { Father FullTime }_{i}+\alpha_{2} \text { Female }_{i}{ }^{*} \text { Father FullTime }_{i}+\gamma X_{i}+\eta_{j}+\varepsilon_{i}
\end{aligned}
$$

The significance of the coefficients on the interaction terms, $\beta_{2}$ and $\alpha_{2}$, reflect whether there is any transmission of role attitudes within the family that differs by gender and the sign indicates its direction, e.g. a positive and significant coefficient $\hat{\beta}_{2}$ indicates that having a mother who actively participates in the labour market affects daughters' performance more than sons', pointing to intergenerational transmission of gender role attitudes from mothers to daughters.

When equation [3] is estimated for the 63 PISA 2009 participating countries we find a positive impact of Mother participate on daughters, but the effect is only marginally significant. However, given that we use the variable Mothers' Participation as an indicator for social norms, it is reasonable to restrict the

${ }^{15}$ Other summary statistics also confirm the similarity of these two variables. The means of Mothers' Participation and FLFP 35-54 are 0.713 and 0.729 respectively and the standard deviation is slightly higher for the former.

${ }^{16}$ In this case we use Father working full-time instead of Father participate since most fathers participate in the labour market $(91.50 \%)$ and the percentage of fathers who are working fulltime (75.40) is more similar to that of the mothers who participate $(70.03 \%)$, and so provides a better indicator of a highly-attached father. 
sample to those countries where female participation in the labour market can be considered an issue in terms of gender attitudes. In other words, in societies where female participation is very high, such us the Nordic countries, the participation of the mother is probably not an adequate indicator of gender roles. Therefore, we restrict the sample to those countries ${ }^{17}$ whose FLFP 15 + levels are below average. Table 6 presents the results for that selected sample of PISA 2009 countries. For clarity of exposition, the sixth row of the table reports the Net effect on girls' scores of Mother participate, which is computed as $\hat{\beta}_{1}+\hat{\beta}_{2}$. This figure, ceteris paribus, gives us a quantitative idea of how much girls may improve their maths score due to having a mother attached to the labour market.

Table 6

Gender Roles - The Impact of Parents' Labour Status on Children's Scores

\begin{tabular}{|c|c|c|c|}
\hline & Average & 25th & 75th \\
\hline \multirow[t]{2}{*}{ 1. Female } & $-29.26^{* * *}$ & $-29.29 * \star \star$ & $-29.08^{\star \star \star}$ \\
\hline & $(1.443)$ & $(1.840)$ & $(1.788)$ \\
\hline \multirow[t]{2}{*}{ 2. Mother Participate } & -0.690 & -2.339 & 0.770 \\
\hline & (1.072) & $(1.392)$ & $(1.230)$ \\
\hline \multirow[t]{2}{*}{ 3. Female* Mother Participate } & $4.695^{\star \star \star}$ & $7.153^{\star \star \star}$ & 1.906 \\
\hline & $(1.378)$ & $(1.703)$ & (1.621) \\
\hline \multirow[t]{2}{*}{ 4. Father Working Full-Time } & $10.276^{\star \star \star}$ & $8.883^{\star \star \star}$ & 10.530 *** \\
\hline & $(1.105)$ & $(1.396)$ & (1.319) \\
\hline \multirow[t]{2}{*}{ 5. Female ${ }^{*}$ Father Full-Time } & 1.468 & 2.205 & -0.245 \\
\hline & (1.477) & $(1.885)$ & (1.784) \\
\hline \multirow[t]{2}{*}{ 6. Net effect on girls: $[2]+[3]$} & $4.005^{\star \star \star}$ & $4.814^{\star \star \star}$ & $2.675^{\star}$ \\
\hline & $(0.984)$ & $(1.235)$ & (1.192) \\
\hline Students & 177,099 & 177,099 & 177,099 \\
\hline Countries & 28 & 28 & 28 \\
\hline$R^{2}$ & 0.407 & 0.230 & 0.251 \\
\hline
\end{tabular}

Notes: Robust standard errors in parentheses ${ }^{* *} p<0.01,{ }^{*} p<0.05,{ }^{*} p<0.1$. Individual level controls, school variables and country fixed effects are included. Israel is taken as the country of reference. Students' final weights are used in the estimations.

Source: Own elaboration.

Several interesting features emerge from Table 6. First, the positive and significant coefficient for the interaction of Female with Mother participate in the first column reveals that on average daughters' scores are higher in families where the mother participates in the labour market ${ }^{18}$. More specifically, the

${ }^{17}$ This sample corresponds to 177,099 students in 28 countries: Albania, Belgium, Bulgaria, Chile, Czech Republic, Colombia, Croatia, Greece, Hungary, Italy, Jordan, Mexico, Poland, Rumania, Dubai, Tunisia, Turkey and Serbia \& Montenegro, France, Israel, Japan, Korea, Lithuania, Luxembourg, Panama, Qatar, Slovak Republic and Spain.

${ }^{18}$ Very similar results are found if we include Mother working full-time instead of Mother participate (full-timers account for $45.40 \%$ of the total sample of mothers and $65.61 \%$ of all working mothers). 
reduction in the gap in maths for those girls is around 16 per cent - computing the ratio between 4.69 and 29.26. Second, the insignificant coefficient of the indicator for Mother participate (throughout the second row) reflects that boys have on average the same scores regardless of whether their mothers work in the labour market. Thus, the net improvement in girls' scores is quite similar to the reduction in the gap, which represents exactly the quantitative average effect of the transmission of role attitudes from mothers to daughters. With regards to the distributional effects, we find a bigger reduction in the gap for lowachieving girls of around 24 per cent - ratio between 7.16 and 29.29, which appears as non-significant for girls at the upper end. One last comment on Table 6 deserves to be highlighted: the fact that the interaction of Female with Father working full-time is not significantly different from zero. Together with the positive and significant coefficient for Father working full-time (throughout the fourth and fifth rows) this reveals that in families where the father works fulltime children perform better but that there is no gender differential in that effect.

\subsection{Robustness Checks and Extensions of the Results}

We end this section with a brief description of some of the robustness checks and extensions conducted to ensure that our findings are robust to different specifications. It could be argued that the results may be driven by the particular selection of countries or by the specification used in the estimation. As a robustness check, we re-estimated the whole analysis for different selected subsamples of countries, in particular for those where Female Participation levels lie below the $25^{\text {th }}$ and the $10^{\text {th }}$ quantiles of the FLFP $15+$ distribution. In the first group this restricted our analysis to 15 countries out of the previous 28 whereas in the most restricted group we ended up with just 6 countries: Chile, Colombia, Italy, Jordan, Tunisia and Turkey. There are 112,714 and 47,098 student observations in the two groups respectively. The results indicate that the transmission effect is indeed larger when we restrict to those countries with particularly low FLFP levels. This is an expected result, as mothers' participation in these countries may indeed be a stronger indicator of gender roles.

Secondly, two different specifications are estimated for the three different samples: in the first one we replace the country fixed effects by the FLFP 15+ level of each country, which to some extent summarizes the degree of gender equality; in the second we introduce the $2009 \log$ GDP per capita and its interaction with Female. As expected, the net effects of mothers' participation on daughters' scores are higher when the first specification is used, since in this way we are comparing societies with the same average level of female participation. In fact, the impact is higher not only for the three selected subsamples described above but also if the entire sample of 63 countries is used instead. However, the percentage of variance explained by this model is much 
lower than when our preferred specification - which includes country fixed effects, is used instead. On the other hand, the effects of the second specification are smaller although still positive and significant in all cases. Furthermore, in no case we do find the interaction between Female and Father full-time to be significant, which reinforces the fact that there is no differential transmission by gender from the father's side.

It could also be asked whether the transmission is actually driven by the parental labour status itself or by other determinants which might be correlated with it. An obvious candidate would be the parents' educational attainment. In order to ensure that our intergenerational transmission results are not driven by parents' education but by the mother's labour market status we run the same regressions as before for all the samples and for the different specifications but with the interactions of Mother participate and Father full-time with Female replaced by those for the education of both parents (University or not). None of the interactions is significant in any of the estimations. Finally, in order to learn more about the transmission mechanism we look at whether the impact of Mother participate on daughters' and sons' maths scores differs according to mothers' educational attainment. To that end we add to the baseline specification of Table 6 an interaction between Mother University and Mother participate and another interaction between Female and the former. A positive and significant coefficient for this last interaction would suggest that the transmission is driven by highly-educated mothers. However, we find no differential effect on transmission due to education, which leads us to conclude that gender roles are transmitted similarly by all participating mothers, and not only by the most highly-educated ones.

In summary, we find that gender role attitudes within the family, as measured by the participation of mothers in the labour market, affect girls' performances positively, suggesting some intergenerational transmission of gender identities or gender roles from mothers to daughters. Furthermore, the effect is found to be stronger for girls at the lower end of the distribution, with a reduction in the maths gap relative to boys of around 24 per cent. In addition, the lower the average female participation level of the country where having a working mother is a clearly distinguishing feature, the stronger this transmission is. Furthermore, we find no significant differential effects by gender of having a father working full-time, indicating that there is no such transmission from fathers to sons. The results are robust to different specifications and subsamples.

\section{CROSS-REGIONAL ANALYSIS WITHIN A SINGLE COUNTRY: SPAIN}

One of the downsides of the international analysis in the previous sections is the huge variability that exists in the evolutionary history of the different 
populations across countries, with biological differences between them being one of the factors potentially responsible for these results. To account for this, Guiso et al. (2008) divide the sample into two groups of countries based on genetic distance ${ }^{19}$, and find that results are substantially unchanged for either groups, which confirms that they are not driven by biological differences across countries. In this section we validate those results within a more comparable scenario, in particular by comparing regions within a country. This, in addition to providing similar historical evolution, focuses on a more homogeneous institutional framework. We choose Spain as the country of analysis since it is the only PISA 2009 participating country that provides a broad enough regional disaggregation. Furthermore, the huge differences in terms of achievement between students from different Spanish regions highlighted in recent literature (See Ciccone \& Fontes 2009; De la Rica \& González de San Román 2012), together with the large gender gaps for the Spanish average already documented in this paper provide enough variability for the analysis. Thus, we can investigate whether girls and boys perform better in more gender-equal regions in Spain, and determine the extent to which the intergenerational transmission of gender role attitudes from mothers to daughters is also an issue among Spanish families once regional variability is accounted for.

\subsection{Data Description}

The 2009 wave provides disaggregated data for 15 different Spanish regions. After excluding Ceuta and Melilla we end up with 23,708 students from 839 schools. Most regions have samples of about 1,500 students and 50 schools, except for the Basque sample ${ }^{20}$ which includes nearly 4,800 students from 180 schools. Sample sizes are 12,068 for boys and 11,640 for girls. Table 7 reports the average maths and reading test scores as well as the gender gaps for each region in 2009. For comparability purposes, the OECD and Spanish averages are also reported, along with the samples of students and schools for which information is available for each region.

A glance at the table indicates remarkable raw differences in both test scores across regions, so the poor results obtained by Spain on average cannot be extrapolated to all regions that participate in the assessment programme. There are regions whose results are above the OECD and national averages, such as Castilla-León, Navarra and the Basque Country, while Andalusia, Murcia and

${ }^{19}$ This genetic measure is based on the frequency of each allele across DNA polymorphisms taken from the History and Geography of Human Genes by Cavalli-Sforza et al. (1996)

${ }^{20}$ The only PISA requirement for regional disaggregation is that the selection of schools and students within each school should be random, but it is left up to each region what size sample they wish to provide. The Basque sample was also the biggest out of the five regions that participated in the 2003 PISA wave. 
the Islands are clearly below the national average and a long way from the OECD average. With respect to the gender gap in achievement, on average girls' maths scores are 19.32 lower than those of boys $(3.72 \%$ less than the mean average score for boys) but girls score 28.66 more in reading $(6.07 \%$ higher than the mean average score for boys). Although boys outperform girls in maths in all regions while girls score relatively better in reading, the width of the gap differs significantly. Interestingly, the fact that the highest maths gender gaps are those of Andalusia and the Islands (the worst-performing Spanish regions) seems to suggest a negative relationship between gender inequality in test scores and average performance that was not so clear in the international analysis in Section 3. Finally, the correlation between the average gender gaps in maths and reading across regions is lower than that across countries at an average of 0.503 .

Table 7

Math and Reading Test Scores and Gender Gaps across Spanish Regions

\begin{tabular}{lcccccc}
\hline & & \multicolumn{2}{c}{ Mean Test Score } & \multicolumn{2}{c}{ Gender Gap } \\
& Students & Schools & Maths & Reading & Maths & Reading \\
\hline Castilla-León & 1.515 & 51 & 515.13 & 503.41 & -15.42 & 31.89 \\
Navarra & 1.504 & 49 & 510.98 & 497.15 & -12.94 & 34.9 \\
Basque Country & 4,768 & 177 & 509.17 & 494.19 & -9.13 & 35.13 \\
Aragón & 1,514 & 52 & 505.03 & 494.38 & -19.17 & 32.76 \\
La Rioja & 1,288 & 46 & 502.73 & 497.89 & -16.94 & 36.4 \\
\hline OECD average & & & 499.70 & 489.81 & -15.22 & 32.79 \\
\hline Madrid & 1,453 & 51 & 496.43 & 504.10 & -12.65 & 35.37 \\
Cantabria & 1,516 & 51 & 495.48 & 488.12 & -15.88 & 35.98 \\
Catalonia & 1,381 & 50 & 494.89 & 497.29 & -22.53 & 26.51 \\
Asturias & 1,536 & 54 & 493.95 & 490.21 & -12.95 & 28.51 \\
Galicia & 1,585 & 54 & 488.38 & 484.52 & -11.8 & 35.43 \\
\hline Spain average & 23,708 & 839 & 483.99 & 483.30 & -19.35 & 28.66 \\
\hline Murcia & 1,321 & 51 & 479.03 & 480.49 & -16.62 & 17.11 \\
Balearics & 1,463 & 52 & 464.15 & 458.20 & -21.83 & 33.07 \\
Andalusia & 1,416 & 51 & 462.73 & 460.53 & -27.12 & 19.85 \\
Canaries & 1,448 & 50 & 433.95 & 448.13 & -15.86 & 23.77 \\
\hline
\end{tabular}

Note: Regions are ranked by their mean maths score. Students' final weights are used.

Source: Own elaboration.

Table 8 looks at the gender gaps at the tails of the distribution range and shows that the gender gap in maths is slightly wider (in absolute terms) for the top percentiles, while the reading gender gap is sharply decreasing over the test score distribution. This is consistent with the international pattern observed in Table 1 . Nevertheless, the variability over the maths gender gap distribution range is lower for the case of Spain. This can be easily checked by computing 
the difference between the $90^{\text {th }}$ and $10^{\text {th }}$ percentiles in both cases. For Spain, the figure is -7.33 while for the international case it is almost double at -14.25 .

Table 8

The Spanish Maths \& Reading Gender Gaps over the Distribution Range

\begin{tabular}{lcccccccc}
\hline & Mean & Std Dev & 5th & 10th & 25th & 75th & 90th & 95th \\
\hline Maths Score & & & & & & & & \\
\hline Boys & 493.54 & 90.37 & 339.47 & 372.18 & 433.72 & 558.35 & 608.12 & 635.91 \\
Girls & 474.16 & 88.98 & 320.77 & 355.83 & 415.8 & 535.84 & 584.44 & 613.58 \\
Gender Gap & $\mathbf{- 1 9 . 3 2}$ & & $\mathbf{- 1 8 . 7}$ & $\mathbf{- 1 6 . 3 5}$ & $\mathbf{- 1 7 . 9 2}$ & $\mathbf{- 2 2 . 5 1}$ & $\mathbf{- 2 3 . 6 8}$ & $\mathbf{- 2 2 . 3 3}$ \\
\hline Reading Score & & & & & & & & \\
\hline Boys & 467.13 & 88.81 & 310.54 & 348.94 & 408.26 & 529.39 & 578.3 & 604.27 \\
Girls & 495.82 & 83.47 & 348.8 & 384.47 & 444.21 & 553.12 & 597.21 & 621.44 \\
Gender Gap & $\mathbf{2 8 . 6 6}$ & & $\mathbf{3 8 . 2 6}$ & $\mathbf{3 5 . 5 3}$ & $\mathbf{3 5 . 9 5}$ & $\mathbf{2 3 . 7 3}$ & $\mathbf{1 8 . 9 1}$ & $\mathbf{1 7 . 1 7}$ \\
\hline
\end{tabular}

Source: Own elaboration.

\subsection{Regional Gender-Equality Measures and Gender Differences in Maths Scores}

Given the important issue under analysis from now we focus on the maths gender gap, as we did in the international case. We construct several regional measures related to gender roles and social norms to explain the gender gap in maths scores across Spanish regions. As in previous sections, we relate gender gaps in test performance across regions in Spain to regional socio-economic characteristics. We classify regions according to five measures of gender equality in line with those used in the international analysis. Except for the women's emancipation index, which is not available at regional level, most of the indicators used here are similar to those in the previous section.

(1) Female political participation in regional parliaments from INE 2009: similar to the political empowerment index in the international analysis.

(2) The Avg ESS index: we construct a regional index of cultural attitudes towards women based on the average level of disagreement with the following statement: "When jobs are scarce, men should have more right to a job than women" across regions. This is taken from the 2008 European Social Survey ${ }^{21}$.

(3) Regional female labour force participation 15+: taken from the Spanish National Institute of Statistics (INE) for 2009.

(4) Regional female labour force participation 25-54: from the same source.

${ }^{21}$ This indicator is similar to the Average World Value Survey Indicator in the previous section, except that it includes the answers to only one of the questions included in its international counterpart (the remaining questions are not available at Spanish regional level). 
(5) Regional gender ratio (Men/Women) for time spent on housework: taken from the latest available wave of the Time Use Survey for Spain (2009).

Table 9 shows that the one-by-one correlations between these measures are generally lower across regions than across countries - See Table 3 for comparison. In particular, there seems to be a high correlation between the Gender Housework Ratio and Female Labour Force Participation (for all women and for the cohort of 25-54). The rest of the correlations are clearly weaker. A look at the sample statistics for the Spanish regional measures reveals that those which show lower correlations are associated with standard deviations above 0.20 and hence much higher than any of the corresponding deviations shown in the sample statistics for the international case - See Table 2. On the other hand, the deviations of the Gender Housework ratio and the Female Labour Force Participation measures are much more similar at around 0.05 .

Table 9

Correlation between regional gender equality measures in Spain

\begin{tabular}{l|ccccc}
\hline & $\begin{array}{c}\text { Political } \\
\text { Emp. }\end{array}$ & $\begin{array}{c}\text { Avg. } \\
\text { ESS }\end{array}$ & $\begin{array}{c}\text { FLFP } \\
\mathbf{1 5 +}\end{array}$ & $\begin{array}{c}\text { FLFP } \\
\mathbf{2 5 - 5 4}\end{array}$ & $\begin{array}{c}\text { Housework } \\
\text { ratio }\end{array}$ \\
\hline Political Empowerment & 1 & & & & \\
Avg ESS Indicator & 0.1509 & 1 & & & \\
FLFP 15+ & 0.0468 & 0.1779 & 1 & & \\
FLFP 25-54 & 0.2241 & 0.3449 & 0.6518 & 1 & \\
Housework ratio & 0.3231 & 0.4098 & 0.4132 & 0.5403 & 1 \\
\hline
\end{tabular}

Source: Own elaboration.

Given that we have only 14 regions, which makes cross-regional analysis highly imprecise, for the estimation exercise we carry out the analysis directly at student level, pooling the sample for all Spanish regions. We follow the same approach as before, estimating the student maths score for a set of individual, family and school variables, together with an indicator of Female and interactions between Female and each of the average regional measures of gender equality equivalent to equation [2] in Section 3. The interaction of the gender dummy with the $2009 \log$ GDP per capita and regional fixed effects are also included. The results are reported in Table 10.

In summary, the Avg ESS index and the Gender Housework Ratio are the main gender equality measures for improving girls' maths scores in Spain. In contrast with the analysis across countries the rest of the interactions here are not statistically significant. Therefore, more gender-equal regions - represented by an increase in the Avg ESS index or an increase in the time that men devote to housework relative to women - are associated with an improvement in maths among girls, thus reducing the negative gap. However, the significance of the coefficient for the interaction term of Female with the Gender Housework Ratio 
disappears in the top quantile of the distribution range. The results here imply that the evidence is weaker across Spanish regions than across countries. This could be explained simply by the lower variability of equality measures at Spanish regional level.

Table 10

The Impact of Regional Gender-equality Measures on Girls' Scores

\begin{tabular}{|c|c|c|c|}
\hline & Average & 25th & 75th \\
\hline \multirow[t]{2}{*}{ Female* Political empowerment } & -14.01 & -32.40 & -11.89 \\
\hline & $(36.07)$ & $(51.60)$ & $(43.85)$ \\
\hline \multirow[t]{2}{*}{ Female* Avg ESS indicator } & $21.57^{\star \star \star}$ & $21.61^{\star \star *}$ & $22.73^{\star \star \star}$ \\
\hline & (5.44) & (7.65) & (8.11) \\
\hline \multirow[t]{2}{*}{ 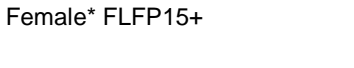 } & 4.55 & -32.61 & -23.81 \\
\hline & $(37.28)$ & $(54.55)$ & $(48.08)$ \\
\hline \multirow[t]{2}{*}{ Female* FLFP $35-54$} & $66.93^{*}$ & 36.17 & 47.88 \\
\hline & $(39.53)$ & $(57.40)$ & $(49.45)$ \\
\hline \multirow[t]{2}{*}{ Female* Housework ratio } & $61.98^{\star *}$ & $72.24^{*}$ & 14.27 \\
\hline & $(31.46)$ & $(41.49)$ & $(43.59)$ \\
\hline
\end{tabular}

Notes: Robust standard errors in parentheses *** $p<0.01, * * p<0.05, * p<0.1$. Individual level controls, school variables and regional fixed effects included. Castilla-León is taken as the region of reference. Students' final weights are used in the estimations. Observations: 19,695.

Source: Own elaboration.

\subsection{The Intergenerational Transmission of Gender Roles}

Next, instead of using regional averages of gender equality measures and interacting them with a gender indicator, we analyse whether individual test scores for Spanish students are affected by mothers' labour market status (as participants or not) and whether this impact differs by gender ${ }^{22}$. To that end we run OLS regressions of the maths test score on a set of demographic, family and school variables and regional fixed effects as well as indicators for Female, Mother Participate and interactions between the two. We also include, as before, Father full-time and an interaction with Female, to see whether there is any intergenerational transmission from the side of the father in Spain. This corresponds to equation [3] in Section 3. Table 11 reports the results.

22 The correlation between Mothers' Participation and FLFP 25-54 across Spanish regions is 0.8591 , which is lower than the cross-country correlation (which is 0.96 ) but also ensures that the mothers in the Spanish sample are representative of the population of women in that age cohort, and that the indicator can be used as a proxy for gender role attitudes. The reason why the correlation is lower now is that data restrictions led us to include younger women, from 25 to 35 , an age interval which cannot include the mothers of our students. 
Table 11

The Impact of Parental Labour Status on Children's Scores in Spain

\begin{tabular}{|c|c|c|c|}
\hline & Average & 25th & 75th \\
\hline \multirow[t]{2}{*}{ Female } & $-42.54^{* * *}$ & $-47.44^{* * *}$ & $-43.18^{* \star *}$ \\
\hline & $(4.05)$ & $(4.75)$ & $(4.93)$ \\
\hline \multirow[t]{2}{*}{ Mother Participate } & 1.54 & -1.07 & 3.34 \\
\hline & $(2.51)$ & $(2.92)$ & $(2.98)$ \\
\hline \multirow[t]{2}{*}{ Female*Mother Participate } & $8.37^{\star \star *}$ & $10.06^{* * *}$ & $7.95^{\star *}$ \\
\hline & (3.49) & (4.13) & (3.92) \\
\hline \multirow[t]{2}{*}{ Father Working Full-Time } & 0.69 & -3.36 & 2.54 \\
\hline & $(2.62)$ & $(3.01)$ & $(3.15)$ \\
\hline \multirow[t]{2}{*}{ Female*Father Full-Time } & 4.94 & 5.32 & 3.78 \\
\hline & (3.68) & (4.26) & $(4.33)$ \\
\hline \multirow[t]{2}{*}{ Net effect on girls } & $9.91^{\star \star *}$ & $8.99^{\star \star *}$ & 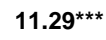 \\
\hline & (2.46) & (3.12) & (2.89) \\
\hline$R^{2}$ & 0.402 & 0.237 & 0.226 \\
\hline
\end{tabular}

Notes: Robust standard errors in parentheses *** $p<0.01,{ }^{* *} p<0.05,{ }^{*} p<0.1$. Individual level controls, school variables and regional fixed effects are included. Castilla-León is taken as the region of reference. Students' final weights are used in the estimations. Observations: 19,695 .

Source: Own elaboration.

Various aspects must be highlighted. First, a positive and significant coefficient for the interaction of Female with Mother participate is found both at the average and in the different quantiles of the distribution range. More importantly, those coefficients are much higher than the corresponding ones in the international estimation in all cases - See Table 6 for comparison. This suggests that the intergenerational transmission of gender role attitudes from mothers to daughters is stronger within Spanish families. However, given that the raw gap in maths is higher in Spain the reduction of the gap is very similar - it goes from 20 to 23 per cent depending on the estimation. Second, the coefficient of Mother participate which reflects the impact of this variable on boys (given that the interaction with Female is already included) is not significant, reflecting that boys' scores are not affected by their mothers' labour status in Spain. As found in the previous section, the fact that the interaction of Father full-time with Female is not significant indicates that there is no specific transmission from fathers to daughters. Finally, the quantile estimations reveal no significant differences in the impact of gender role attitudes throughout the score distribution for the Spanish case.

Next we look further into the transmission mechanism, as before, and examine whether there is a differential effect of Mother participate on girls' performances depending on the educational attainment of their mothers. An indicator is included for university/non-university education of the mother as well as her participation status. In contrast with the results in the previous section, the transmission of gender role attitudes in Spain is driven by highly- 
educated mothers, since those girls whose mothers participate in the labour market and in addition have a university education perform significantly better in maths with respect to boys - in particular, 8.41 score points better, which amounts to a 23 per cent reduction of the gap.

\section{CONCLUSIONS}

For over a decade, researchers have paid attention to gender differentials at early stages of life (Goldin 1994; Hausmann et al., 2008) as potential indicators of gender inequalities later in life, more specifically, in the labour market. Two examples of these early stage gender inequalities are (i) the underperformance of girls with respect to boys in maths competencies in PISA tests, which students take when they are about 15 years old; and (ii) the under-representation of women in technical careers such as engineering and maths. Both facts have been commonly observed in most industrialised countries, and indeed are likely to be correlated. Furthermore, these gender differences clearly affect subsequent professional careers and may help explain the gender differentials observed in the labour market in terms of wages, promotion, job stability and status.

Some argue that nature is the main determinant of these early gender differentials. However, another line of research -the social stratification hypothesisargues that gender norms may be behind them. In this paper we follow the latter line of research and address the extent to which girls' maths performance improves in more gender equal societies, countries or regions within a country. The transmission of gender role attitudes across generations has also been the focus of a great deal of recent research on labour market outcomes. Having a working mother has been found to influence not only children's behaviour but also the gender role attitudes of adolescents strongly. However the role of culture and its implications for economic behaviour across generations is relatively unexplored in empirical studies on scholastic achievement. Our paper seeks to help fill this gap.

We make use of the 2009 PISA survey, which provides information on the performance of male and female students from 63 different OECD and partner countries. With this dataset, we provide empirical support for the social gender stratification hypothesis at international level and extend the analysis to relate social norms to gender differences in maths scores across regions within the same country, which constitutes a more homogeneous institutional setting. We make use of regional variation in Spain since it is the only country in PISA 2009 where regional disaggregation enables analysis across regions to be conducted. Furthermore, we investigate whether gender role attitudes within the family are transmitted from generation to generation, and measure the implications of such cultural transmission in terms of children's scholastic achievement. 
As a descriptive device, we find that in most PISA 2009 participating countries and in all Spanish regions there is a significant gender gap in both maths and reading competencies. In particular, girls perform worse than boys in maths and better in reading. These gaps are exacerbated in detriment of girls among high-achieving students. The estimation exercises focus on the maths gender gap given the nature of the questions under analysis and the high correlation observed between the two gaps.

In order to test the gender stratification hypothesis we construct several gender equality measures at both country and regional levels, some of which have been already used in the relevant literature, which help us to validate new measures that we introduce. We find a positive and significant correlation between those indicators and the maths gender gap, suggesting that in more gender-equal societies - be they countries or regions within a country - girls reduce the gap in maths. This relationship is more apparent across countries than across regions in Spain.

Secondly, gender role attitudes within the family, as measured by the participation or not of mothers in the labour market, is found to affect girls' maths scores positively, suggesting some intergenerational transmission of gender identities from mothers to daughters, an effect that is bigger for girls at the lower end of the test score distribution range. This effect is stronger in countries with low female labour force participation (below average), and hence in societies where such mothers "make a difference" in terms of gender role attitudes relative to their counterparts. Interestingly, such transmission is found to be even stronger when we restrict the analysis to Spain, which belongs to the group of low-participating countries. In Spain it is mainly driven by the most highly-educated participating mothers. However, we find no significant differential effects by gender from having a father working full-time in the pooling of countries or in Spain, indicating that there is no such differential transmission from the father's side.

One possible interpretation of the transmission from the mother that has gained popularity over the last ten years (Bertrand, 2010) and which is highly consistent with our results lies on the idea that agents' decisions are driven by a gender identity that implies strong behavioural prescriptions indicating what it is appropriate for men and for women to do. Thus, those mothers who participate in the labour market are somehow breaking away from the traditional view of men working in the labour force and women staying at home - with much more intensity in societies where participating is not so common for women. Then, with this behaviour mothers transmit to their daughters this break with traditional gender roles, which makes the daughters feel that they can also compete in those subjects a priori better suited to boys. This ultimately leads to girls developing better maths skills and hence reducing the gap with boys in 
maths. Another possible interpretation concerns differences in effort at school between girls whose mothers have different levels of participation in the labour market, but unfortunately we cannot test this hypothesis due to the lack of suitable information about effort and given the potential endogeneity problem associated with the unobservables of both mothers and daughters.

\section{BIBLIOGRAPHY REFERENCES}

BASU A. (2002). "Why Does Education Lead to Low Fertility? A Critical Review of Some of the Possibilities". World Development, 30, 1779-1790.

BAKER, D. P. \& JONES, D. P. (1993). "Creating gender equality: Cross national gender stratification and mathematical performance". Sociology of Education, (66) 91-103.

BERTRAND, M. (2010). "New Perspectives on Gender". Chapter 17 Handbook of Labor Economics, Volume 4b.

BRATTI, M., CHECCHI, D. \& FILIPPIN, A. (2007). "Geographical differences in Italian students' mathematical competencies: evidence from PISA 2003". Giornale degli Economisti e Annali di Economia (66) 3: 299-333.

BURT, K.B, \& SCOTT, J. (2002). "Parent and Adolescent Gender Role Attitudes in 1990s in Great Britain". Sex Roles, 46, 239-45.

CECCI, S. and W. WILLIAMS (2007). "Why Aren't More Women in Science?". American Psychological Association, Washington, US.

CICCONE, A. \& GARCIA-FONTES, W. (2009). "The quality of the Catalan and Spanish education systems: A perspective from PISA". IESE Research Papers D/810, IESE Business School.

DE LA RICA, S. \& GLEZ DE SAN ROMÁN, A. (2012). "Determinantes de las diferencias regionales en el rendimiento académico en España: PISA 2009". In Villar Notario, A. (Coord.): Educación y Desarrollo PISA 2009 y el sistema educativo español. Chapter 8. Madrid: Fundación BBVA.

DOEPKE, M. \& TERTILT, M. (2009). "Women's liberation: What's in it for men?". Quarterly Journal of Economics, 124, 1541-91.

DOLLAR, D. \& GATTI, R. (1999). "Gender Inequality, Income and Growth: Are Good Times Good for Women?". Policy Research Report on Gender and Development Working Paper Series No. 1, World Bank, Washington.

FARRÉ, L. and F. VELLA (2013). "The intergenerational transmission of gender role attitudes and its implications for female labor force participation". Economica, 80, 219-247.

FERNANDEZ, R. FLOGI, A. \& C.OLIVETTI (2004). "Mothers and Sons: Preference Formation and Female Labor Force Dynamics". Quarterly Journal of Economics, 119, 1249-99.

FORTIN, N. (2005). "Gender Role Attitudes and the Labour-Market outcomes of Women across OECD countries". Oxford Review of Economic Policy, vol. 21 n 3.

FRYER, R. \& LEVITT, S. (2009). "An Empirical Analysis of the Gender Gap in Mathematics." American Economic Journal: Applied Economics. 
FUCHS, T. \& WOESSMANN, L. (2007). "What Accounts for International Differences in Student Performance? A Re-Examination Using PISA Data". Empirical Economics, No. 32 (2), pp. 433-464.

GALLAGER, A.M. \& J.C. KAUFMAN. (2005). "Gender differences in mathematics: An integrative psychological approach". NY: Cambridge University Press, pp.316-332.

GOLDIN, C. (1994). "The U-Shaped Female Labor Force Function in Economic Development and Economic History." In T. P. Schultz, (ed.): Investment in Women's Human Capital and Economic Development. Chicago, IL. University of Chicago Press, pp. 61-90.

GUISO, L., MONTE, F., SAPIENZA, P. \& ZINGALES, L. (2008). "Culture, Gender and Math". Science, 320(5880): 1164-1165.

HAUSMANN, R., TYSON, L. \& ZAHIDI, S. (2008). "The Global Gender Gap Report 2009". Geneva, Switzerland: World Economic Forum.

KLASSEN, S. (2002). "Low Schooling for Girls, Slower Growth for All? Cross Country Evidence on the Effect of Gender Inequality in Education on Economic Development". World Bank Economic Review, 16, 345-373.

KUCIAN, K., T. LOENNEKER, T. DIETRICH, E. MARTIN \& M. VON ASTER. (2005). "Gender differences in brain activation patterns during mental rotation and number related cognitive tasks". Psychology Science, Vol. 47, pp. 112-131.

LAWTON, C.A. \& HATCHER, D.W. (2005). "Gender differences in integration of images in visuospatial memory". Sex Roles, 53 (9-10), pp. 717-725.

PERI, G. \& M. ANNELI (2012). "Non-Academic Skills, Choice of Partner and Peer/Teacher effects as determinant of the Gender Gap in the choice of College Major". In Boeri, T. (ed.): Gender Gap in the Labor Market among Highly Educated: The role of Discrimination, Family and College Major, Forthcoming, 2013.

RIEGLE-CRUMB, C. (2005). "The cross-national context of the gender gap in math and science". In L. Hedges \& B. Schneider (Eds.). The social organization of schooling pp. 227-243.

SINGER, J. M. \& J. E. STAKE (1986). "Mathematics and self-esteem: Implications for women's career choice". Psychology of Women Quarterly 10:339-352.

SPELKE, E.S. (2005). "Sex differences in intrinsic aptitude for mathematics and science? A critical review". American Psychologist 60(9), 950-958.

SCHULTZ, T.P. (2002). "Why Governments Should Invest More to Educate Girls". World Development, 30, 207-225. 
